\title{
ANALYSIS OF IODINE RELEASE FROM THE DEFECTIVE FUEL ELEMENTS OF THE RBMK-1500 REACTOR
}

\author{
G. Klevinskas, L. Juodis, R. Plukienè, A. Plukis, and V. Remeikis \\ Institute of Physics, Savanoriu 231, LT-02300 Vilnius, Lithuania \\ E-mail: jugintas@gmail.com
}

Received 27 April 2007; revised 25 May 2007

\begin{abstract}
The results of modelling and analysis of iodine release to the main circulation circuit of the RBMK-1500 reactor are presented. General approach proposed by Lewis and Husain for the CANDU reactor primary coolant activity prediction was applied. Specific features of the RBMK-1500 coolant activity measurement were assessed. Non-stationary activity measurement conditions were identified and quantified with corresponding correction factors. Parameter values of the adapted model are comparable with those characteristic of CANDU reactor defective fuel.
\end{abstract}

Keywords: nuclear fuel, fission products, diffusion, radionuclide release mechanisms, iodine

PACS: $28.41 . \mathrm{Kw}, 83.80 .-\mathrm{k}$

\section{Introduction}

Operation of a nuclear power plant (NPP) is connected with the generation of large amounts of radionuclides in the nuclear fuel. Some fraction of them is released to the main circulation circuit (MCC) as a result of fuel cladding defects. In case of large defect of one fuel rod, the activity of fission products (FP) in MCC can rise by up to two orders of magnitude [1]. This is unacceptable from the point of view of radiation protection of the plant personnel and public. Some FP are especially long-lived, such as ${ }^{129} \mathrm{I},{ }^{135} \mathrm{Cs}$, etc. Relatively large amounts of ${ }^{129}$ I shall be collected in ion exchange resins which later on shall be cemented and disposed off in near-surface disposal facilities. Moreover, knowledge of ${ }^{129}$ I content is essential for the assessment of radiological impact of the long-term disposal facility on the general public and the environment. If no fuel defects exist, FP are accumulated in the gap between fuel pellets and the zirconium alloy cladding. Knowledge of the content of FP in the fuel gap is important to the safety assessment of nuclear fuel handling and its storage and disposal. Estimation of FP behaviour is of high practical importance to the nuclear power plant operation, decommissioning, and radioactive waste management.

From a practical viewpoint, the characterization of the MCC inventory and related solid NPP waste is quite a difficult task due to the low radiation energy of some radionuclides (e.g., ${ }^{90} \mathrm{Sr},{ }^{129} \mathrm{I},{ }^{135} \mathrm{Cs}$ ), so-called difficult-to-measure radionuclides (DTMR) [2]. For inventory determination of DTMR, the scaling factor analysis involving modern experimental techniques is applied. On the other hand, activity of DTMR can be determined using an appropriate mathematical model of radionuclide release and combining it with the measurement results of other nuclide activities. Behaviour of radionuclides in the MCC coolant is mainly determined by their chemical properties. Therefore, release of radionuclides from nuclear fuel and behaviour in the reactor MCC can be divided into several groups according to their volatility, chemical and phase state. Three main groups of fission products can be distinguished: noble gases $\mathrm{Ar}, \mathrm{Xe}, \mathrm{Kr}$, volatile fission products $\mathrm{I}, \mathrm{Br}$, $\mathrm{Cs}, \mathrm{Rb}, \mathrm{Te}, \mathrm{Se}, \mathrm{Sb}$, and non-volatile fission products $\mathrm{Ba}, \mathrm{Sr}, \mathrm{Zr}, \mathrm{Nb}, \mathrm{Ru}, \mathrm{Rh}, \mathrm{Pd}, \mathrm{Mo}, \mathrm{Tc}, \mathrm{Y}, \mathrm{La}, \mathrm{Ce}, \mathrm{Pr}, \mathrm{Nd}$, $\mathrm{Pm}, \mathrm{Sm}$ [3]. FP of a particular group will behave similarly. Moreover, isotopes of any element will be defined by characteristic migration parameters, e.g., all isotopes of iodine can be characterised by the diffusion coefficient, release rate from defective fuel, and the clean-up rate in ion exchange resins [4]. Therefore, measurement of some easy-to-measure radionuclides can give us information on the migration properties and furthermore, activities of DTMR in the reactor MCC coolant. The purpose of this work is to evaluate the release of iodine isotopes from the RBMK-1500 reactor fuel-to-clad gap to the MCC coolant. A model for 
the CANDU reactor primary circulation circuit [4] is adapted for the RBMK-1500 case taking into account all activity measurement and reactor specifics outlined in the following sections.

\section{RBMK-1500 reactor specifics}

The Ignalina NPP has two RBMK-1500 reactors: one is operating and one is in cold shutdown. Both of them belong to the most advanced version of the RBMK reactor design series. Compared to other types of RBMK type reactors, they are more powerful (1500 MW versus 1000 MW electric power operating in the Russian Federation), and units are provided with an improved Accident Confinement System. The RBMK-1500 reactor is fuelled by a graphitemoderated, water-cooled reactor core having the thermal power generation capacity of $4800 \mathrm{MW}$. It is designed to provide saturated steam at the pressure of 7.0 MPa. The fuel is pellets formed of low enrichment $\mathrm{UO}_{2}$ and loaded into the $13.6 \mathrm{~mm}$ diameter zirconium alloy cladding E110. Initial enrichment was 2\%, from 1997 reload fuel was $2.4 \%$, later on $2.6 \%$, and recently the fuel of $2.8 \%$ enrichment is used. Moreover, in order to improve the reactor operational reactivity characteristics, burnable poisonous erbium is used [5]. Fuel clusters are made up of 18 fuel rods and each is positioned in an individual vertical fuel channel. There are 1661 vertical fuel channels having an active fuel length of $7 \mathrm{~m}$. The design fuel burnup for $2 \%$ enrichment fuel was $21.6 \mathrm{MW} \mathrm{d} / \mathrm{kg} \mathrm{U}$, though from 1986 it was reduced because of safety imposed restrictions related to minimizing the steam reactivity coefficient. The actual fuel burnup is about $16 \mathrm{MW} \mathrm{d} / \mathrm{kg} \mathrm{U}$ for fuel with $2 \%$ enrichment, and not less than $21 \mathrm{MW} \mathrm{d} / \mathrm{kg} \mathrm{U}$ for fuel with $2.4 \%$ enrichment. The fuel clusters are cooled by water which enters at the bottom at subcooling of $30^{\circ} \mathrm{C}$ and exits the channels at an average steam volume fraction of about $76 \%$. The nominal coolant flow rate at the design power is $10^{4} \mathrm{~kg} / \mathrm{s}$ [6]. Essential parameters characterizing the reactor operation and fuel are summarized in Table 1. The coolant channels penetrating the reactor core are divided into two essentially independent cooling loops: one contains 830 and the other 831 vertical channels with fuel assemblies. Each loop is provided with four main circulation pumps, one of which is kept in reserve during normal operation [6].

In the analysis of emergency conditions with regard to nuclear fuel failures, the RBMK-1500 design limits of fuel element failure are based on the following safety criteria: the design limit of fuel element failure

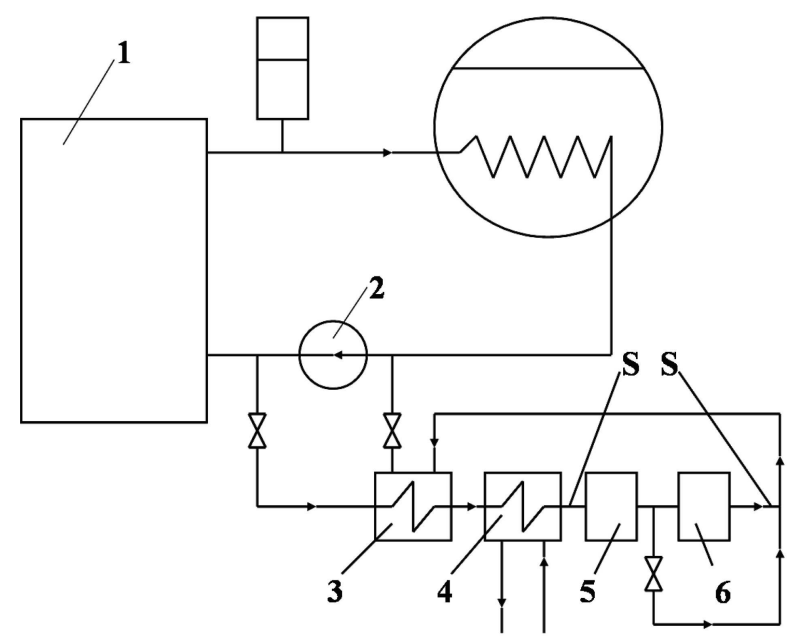

Fig. 1. Principal layout of the water bypass purification system with ion exchange filters of the RBMK type reactor [9]. 1 is reactor, 2 is main circulation pump, 3 is regenerative heat exchanger, 4 is cooling with condensate, 5 is cation filter, 6 is anion filter, $S$ mark sampling points.

under normal operating conditions is $1 \%$ of fuel elements with gas leakage-type defects and $0.1 \%$ of fuel elements having defects resulting in direct contact between the coolant and fuel [7]. Specific activity of fission products in the fuel-to-clad gap and further in the reactor coolant depends on many factors, such as the number of defective fuel elements, reactor power history, fuel burnup, and the reactor coolant purification system $[4,8]$.

High purity of the coolant water is achieved in the RBMK-1500 type reactors by means of the installed bypass water purification system (bypass filters). Part of the water is taken from the MCC, cooled down, and filtered by a mechanical filter and an ion exchanger in the purification bypass [6]. Its main tasks are as follows: (i) purification of MCC water from dissolved salts that occur due to constant filling of the MCC with feedwater and which accumulate in MCC due to steam regeneration; (ii) cleaning of MCC water from oil and corrosion products from construction materials of MCC, steam, and condensate-feeding systems, and (iii) maintenance of MCC water quality so that it does not exceed the established operational parameters.

A principal layout of the RBMK type reactor water bypass purification system with ion exchange filters is given in Fig. 1. Due to its importance the reactor water bypass purification system is assigned to systems relevant to nuclear safety [9].

The reactor bypass water purification system allows decreasing the concentration of fission products, activated ion salts, and corrosion products in the MCC water from two to four orders of magnitude. During the 
Table 1. Essential parameters characterizing the RBMK-1500 reactor operation and fuel [6].

\begin{tabular}{lc}
\hline Coolant & water (steam-water mixture) \\
Fuel & uranium dioxide \\
Initial fuel enrichment with ${ }^{235} \mathrm{U}, \%$ & $2.0^{*}$ \\
Edge pellet enrichment with ${ }^{235} \mathrm{U}, \%$ & 0.4 \\
Fuel burnup, $\mathrm{MW} \mathrm{d} / \mathrm{kg}$ & $21.6^{* *}$ \\
Fuel pellet density, $\mathrm{kg} / \mathrm{m}^{3}$ & 10400 \\
Fuel pellet diameter, mm & 11.5 \\
Fuel pellet length, mm & 15 \\
Pellet central orifice diameter, mm & 2 \\
Average linear power rating, $\mathrm{kW} / \mathrm{m}$ & 21.8 \\
Mass of fuel within fuel element, $\mathrm{kg}$ & 3.5 \\
Number of fuel assemblies in the reactor & 1661 \\
Mass of uranium within fuel pellet, $\mathrm{kg}$ & 111.2 \\
Mass of uranium within edge fuel pellet, $\mathrm{kg}$ & 1.016 \\
Maximum permissible power of fuel channel, $\mathrm{MW}$ & 4.25 \\
Number of main circulation pumps & 8 \\
Capacity of main circulation pumps, $\mathrm{m}^{3} / \mathrm{s}\left(\mathrm{m}^{3} / \mathrm{h}\right)$ & 2600 \\
Maximum acceptable temperature at centre of fuel pellet, ${ }^{\circ} \mathrm{C}$ & 760 \\
Maximum acceptable graphite stack temperature, ${ }^{\circ} \mathrm{C}$ & 700 \\
Maximum acceptable fuel cladding temperature, ${ }^{\circ} \mathrm{C}$ & 650 \\
Maximum acceptable fuel channel temperature, ${ }^{\circ} \mathrm{C}$ & $260-266$ \\
Coolant temperature at fuel channel inlet, ${ }^{\circ} \mathrm{C}$ & $177-190$ \\
Feedwater temperature, ${ }^{\circ} \mathrm{C}$ & 6.9 \\
Pressure at separator drum, MPa & 8.5 \\
Pressure at pressure header, $\mathrm{MPa}$ & $1.805-2.22(6500-8000)$ \\
\hline
\end{tabular}

* Now the fuel is being changed to 2.4-2.8\% enrichment fuel with erbium.

** $2 \%$ fuel enrichment with ${ }^{235} \mathrm{U}$.

reactor operation, the purification of MCC water is carried out continually. Some of the main physical parameters of the installation of the RBMK reactor bypass water purification system are provided in Table 2 .

\section{Fission product release from defective fuel elements}

During operation of a nuclear reactor a significant amount and variety of FP are generated in the uranium dioxide pellets and migrate further to the fuel-to-clad gap. Two types of FP release are distinguished: temperature dependent diffusion and fission induced athermal recoil and knockout of FP. Furthermore, two sources of FP contribute to the MCC coolant activity: release of FP from fuel pellets through cladding defects and from fuel debris in the MCC coolant. An overview of the methods developed for investigating the migration behaviour of fission products in $\mathrm{UO}_{2}$ fuel is provided in [10].

Diffusion due to high fuel temperature is the governing process of FP release from fuel pellets under reactor operation conditions. FP are released from the uranium dioxide fuel into the free void space (fuel-toclad gap) within the fuel element via solid-state lattice diffusion. The diffusion coefficient is a function of at least temperature, fission rate, burnup, and stoichiometry [11-13]. In particular, investigations have shown that for fuel ratings larger than $20 \mathrm{~kW} / \mathrm{m}$ diffusion is the primary mode of release from the $\mathrm{UO}_{2}$ fuel (in case of fuel rod failures, diffusion is enhanced because of fuel oxidation by steam) [8]. The average RBMK-1500 linear power rating is $21.8 \mathrm{~kW} / \mathrm{m}$ [6]. Furthermore, the FP release can be enhanced by the cracking of fuel pellets due to reactor shutdown events and the increased fuel pellet surface [14].

Athermal FP release occurs by surface fission processes followed by the recoil of fission fragments from fuel matrix [8]. Another temperature-independent process of release is knockout, when either a primary fragment or energetic particle created in a collision cascade interacts elastically with a fission product atom. The FP recoil and knockout from fuel pellets do not significantly contribute to the gap inventory [4], the actual contribution to the total FP release is less than $1 \%$ of the generated gas $[15,16]$. However, due to lower temperatures of fuel debris, only direct recoil is an important mechanism of release into the MCC coolant from uranium contamination deposited on in-core surfaces [4].

This rationale is incorporated into the model of FP release to the MCC coolant proposed by [4]. Below 
Table 2. Main physical parameters of the RBMK reactor bypass water purification system [9].

\begin{tabular}{lc}
\hline Parameter & Value \\
\hline Operational efficiency, $\mathrm{m}^{3} / \mathrm{h}$ & $200-400$ \\
Number of multiple filling perlite filters & 5 per unit \\
Operational efficiency of single multiple filling perlite filter, $\mathrm{m}^{3} / \mathrm{h}$ & $30-100$ \\
Number of combined filters & 2 per unit \\
Operational efficiency of combined filter, $\mathrm{m}^{3} / \mathrm{h}$ & $100-200$ \\
Number of filters-catchers & 1 per unit \\
Operational efficiency of filters-catchers, $\mathrm{m}^{3} / \mathrm{h}$ & $100-400$ \\
Type of ion exchange resin for combined filter & Cationite-Lewatit $\mathrm{S} 100 \mathrm{H}$ and \\
& Anionite-Lewatit M5400KR/0H \\
Volume, $\mathrm{m}^{3}$ & 3 per filter \\
Type of powdery ion exchange resin for multiple filling perlite filter & Suprex H21 or Microlite MB21 \\
Dry mass, kg & 25 per filter \\
\hline
\end{tabular}

we reproduced the main assumptions and results of this model in order to predict the RBMK-1500 MCC coolant activity.

\section{RBMK-1500 MCC coolant activity measurements}

Due to the fact that the concentrations of radionuclides in MCC water are relatively low, the sample is subjected to evaporation before the gross activity measurement. Use of radiochemical chromatography allows extracting the radionuclides of interest ${ }^{131} \mathrm{I},{ }^{132} \mathrm{I}$, ${ }^{133} \mathrm{I},{ }^{134} \mathrm{I},{ }^{135} \mathrm{I},{ }^{137} \mathrm{Cs}$, and other fission and activation products from one sample.

Water samples taken from the MCC are measured by means of $\beta$ and $\gamma$ spectroscopy. Content of $\beta$ activity and radionuclide inventory in water samples at the Ignalina NPP are measured once per week and once every two weeks. During shutdown of the reactor for maintenance, additional measurements of water samples are performed. If the control system of fuel integrity detects defective fuel elements in the reactor core, water samples are taken in approximately 10 hours [17]. For each sample a separate set of chemical vessels is used. Before the use of the vessels, they are checked against contamination with $\beta$ particles. The samples are taken at special MCC sampling points (see Fig. 1 for details). The volume of the MCC water sample taken for spectroscopy measurements shall be not less than 0.11 . The volume of MCC water samples taken for evaporation and subsequent measurement of dry residues with the radiometric equipment shall be not less than 0.011 [17]. Water samples taken from MCC and bypass water purification system are hermetically sealed and thereafter they are measured in sealed measurement glasses in 30 minutes. The activity of MCC water samples is recalculated by the software for the moment of their sampling. For radiometric measurement the sample is evaporated until dry residue. Specific activities of radionuclides in the residue are measured with the radiometric device KPK-1 [18]. The gamma spectrometric measurements of radionuclide specific activities in water samples with their activities can be carried out in the range from 3.7 to $37 \cdot 10^{5} \mathrm{~Bq} / 1$ of water samples with the volume range from 0.1 to 1.01 . The $\beta$ scintillation counter is capable of measuring the activity of sampled and evaporated residue in the range of $220 \mathrm{~Bq} / 1-4.8 \mathrm{MBq} / 1$ (measurement time $100 \mathrm{~s}$ and $10 \mathrm{~s}$ accordingly, volume of dry residue is $0.001 \mathrm{l}$ ). For measurements of low activities of $\alpha$ and $\beta$ emitters, the radiometric device for measurement of low activities is used (measurement time $100 \mathrm{~s}$, volume of the evaporated water sample 0.11 ). It is capable of measuring the activities of radionuclides from 0.6 to $185 \mathrm{kBq}$ [19].

\section{Model of FP activity in the reactor MCC}

For the determination of iodine release to the RBMK1500 reactor MCC coolant we applied a general approach proposed in [4] for the CANDU reactor primary coolant activity prediction. The process of radionuclide concentration $C$ distribution, generation with the rate $g$, and release from the fuel grains with radius $a$ is governed by the diffusion equation [4]

$$
\frac{\partial C}{\partial t}=\frac{D}{r^{2}} \frac{\partial}{\partial r}\left(r^{2} \frac{\partial C}{\partial r}\right)-\lambda C+g
$$

where $\lambda$ is the radioactive decay rate constant, $D$ is the diffusion coefficient of a certain fission product in the fuel matrix. The initial conditions for Eq. (1) are

$$
C(r, 0)=0,0<r<a, \quad t=0 \text {. }
$$


Boundary conditions determine the concentration in the centre of the grain sphere and on its surface:

$$
\begin{aligned}
& C(0, t)=\text { finite }, \quad r=0, \quad t>0, \\
& C(a, t)=0, \quad r=a, \quad t>0 .
\end{aligned}
$$

The solution of Eq. (1), with conditions (2)-(4), is the dependence of the ratio of the release rate $R$ to birth rate $B$ of FP on the effective diffusion coefficient and decay rate function. In case of short-lived FP, the solution is a well known Booth relation:

$$
\frac{R}{B}=3\left(\frac{D^{\prime}}{\lambda}\right)^{1 / 2},
$$

where the effective diffusion coefficient $D^{\prime}=D / a^{2}$.

For long-lived fission products, the release to birth rate ratio is

$$
\frac{R}{B}=\left[1-\frac{6}{\pi^{2}} \sum_{n=1}^{\infty} \frac{\mathrm{e}^{-n^{2} \pi^{2} \tau}}{n^{2}}\right]
$$

where $\tau=D^{\prime} t$.

\subsection{Iodine activity change in the presence of fuel defect}

Inventory of fission products in the fuel-to-clad gap $\left(N_{\mathrm{g}}\right)$ and the reactor coolant $\left(N_{\mathrm{c}}\right)$ can be determined by a mass balance of the source release from both defective fuel $\operatorname{rod}(\mathrm{s})$ and uranium contamination and losses due to radioactive decay and coolant purification [4]:

$$
\begin{gathered}
\frac{\mathrm{d} N_{\mathrm{g}}}{\mathrm{d} t}=R_{\mathrm{dif}}-(\lambda+\nu) N_{\mathrm{g}}, \\
\frac{\mathrm{d} N_{\mathrm{c}}}{\mathrm{d} t}=R_{\mathrm{c}}^{t}-\left(\lambda+\beta_{\mathrm{p}}\right) N_{\mathrm{c}} .
\end{gathered}
$$

Here $\nu$ is the gap escape rate coefficient, $R_{\text {dif }}$ is the diffusive release from the source matrix, $\beta_{\mathrm{p}}$ is the coolant purification rate constant $\left(s^{-1}\right) \cdot \beta_{\mathrm{p}}=f_{\mathrm{p}} \varepsilon_{\mathrm{p}} / M$, where $f_{\mathrm{p}}$ is the cleanup system flow rate $(\mathrm{kg} / \mathrm{s}), \varepsilon_{\mathrm{p}}$ is the cleanup system efficiency, and $M$ is the mass of water $(\mathrm{kg})$ in the MCC. The total release rate $R_{\mathrm{c}}^{t}$ into the coolant is

$$
R_{\mathrm{c}}^{t}=R_{\mathrm{c}}(t)+R_{\mathrm{rec}},
$$

where $R_{\mathrm{c}}(t)$ is the release rate from defective fuel $\operatorname{rod}(\mathrm{s})$ and $R_{\text {rec }}$ is from tramp uranium in the coolant. The concentration equilibrium of the short-lived fission products is reached rapidly and the release rate is approximated by the following relation [4]:

$$
\left(\frac{R}{y}\right)_{\mathrm{c}}=\left(\frac{\nu}{\lambda+\nu}\right) \frac{A}{\sqrt{\lambda}}+c
$$

where $A=x \cdot 3 \sqrt{D} F_{\mathrm{f}}, c=(1 / 2) F_{\mathrm{t}}$, and $y$ is the yield of corresponding isotope. Here $x$ is the number of defective fuel rods, $F_{\mathrm{t}}$ is the fission rate in the tramp uranium $\left(s^{-1}\right)$, and $F_{\mathrm{f}}$ is the average fission rate per defective rod $\left(s^{-1}\right)$.

The release model in Eq. (10) can be fitted to the measured $(R / y)_{\text {meas }}$ ratio derived from steady-state coolant activity measurements via Eq. (8) [4]:

$$
\begin{aligned}
R_{\text {meas }} & =\left(\lambda+\beta_{\mathrm{p}}\right) N_{\mathrm{c}} \Rightarrow \\
\left(\frac{R}{y}\right)_{\text {meas }} & =\left(\frac{\lambda+\beta_{\mathrm{p}}}{\lambda}\right) \frac{A_{\mathrm{c}}}{y},
\end{aligned}
$$

where $A_{\mathrm{c}}=\lambda N_{\mathrm{c}}$ is the measured coolant activity (Bq) of a given isotope.

\subsection{FP release to the MCC coolant of RBMK-1500 reactor}

The same approach as described above was used to assess iodine release from defective fuel elements to the MCC coolant of the Ignalina NPP RBMK-1500 reactor. In order to apply the above outlined approach, we analysed specific features of the RBMK-1500 reactor to assess whether the steady state condition can be applied in the RBMK reactor case. An indicative parameter of fuel integrity is the radioactivity level of the coolant leaving the reactor core [7]. The MCC of RBMK-1500 reactor is equipped with a system for permanent inspection of specific activity of each fuel assembly channel coolant. The existence of large fuel cladding defects can be correlated with the large increase of iodine isotopes activity, mainly ${ }^{131} \mathrm{I},{ }^{132} \mathrm{I}$, ${ }^{133} \mathrm{I},{ }^{134} \mathrm{I}$, and ${ }^{135} \mathrm{I}$ in the coolant. In case the monitoring system detects the increase of the reactor coolant activity during the reactor operation, the fuel channel with the defective assembly is replaced by the new one at full reactor power operation by means of the refuelling machine [6]. The detailed laboratory measurements of MCC water samples are carried out in up to 10 hours after detection of the fuel failure. Therefore, the steady state conditions even for short-lived fission products probably are not achieved in this short period of time after the defect occurrence.

We developed a simplified model to evaluate how much the concentrations of iodine isotopes would differ from those when equilibrium between the gap of the damaged fuel element and MCC water is reached. For this relatively short period of time from the defect occurrence to the concentration equilibrium in the coolant, when the reactor is operated at the constant 
Table 3. Correction factor $F_{i}$ for activity of iodine isotopes.

\begin{tabular}{lccccc}
\hline Isotope & ${ }^{131} \mathrm{I}$ & ${ }^{133} \mathrm{I}$ & ${ }^{135} \mathrm{I}$ & ${ }^{132} \mathrm{I}$ & ${ }^{134} \mathrm{I}$ \\
\hline Decay rate $\lambda, \mathrm{s}^{-1}$ & $9.98 \mathrm{E}-07$ & $9.26 \mathrm{E}-06$ & $2.93 \mathrm{E}-05$ & $8.44 \mathrm{E}-05$ & $2.20 \mathrm{E}-04$ \\
Correction factor $F_{i}$ & 1.62 & 0.85 & 0.90 & 0.99 & 1.00 \\
\hline
\end{tabular}

power level, it can be assumed as the first order approximation that the release rate from the fuel matrix is constant in time, $R_{\text {dif }}=$ const. We also neglect the release from the tramp uranium, which is by several orders of magnitude lower than that from the defective fuel element. The solutions for Eq. (7) (before the appearance of the defect and afterwards) and Eq. (8) with the substitution $R_{\mathrm{c}}^{t}(t) \rightarrow R_{\mathrm{c}}=\nu N_{\mathrm{g}}(t)$ are as follows:

$$
\begin{aligned}
N_{\mathrm{g}}^{\mathrm{tight}}(t)= & \left(1-\mathrm{e}^{-(\lambda+\nu) t}\right) \frac{R_{\text {dif }}}{\lambda+\nu}, t \leq t_{\text {def }} \\
N_{\mathrm{g}}^{\text {def }}(t)= & \left(N_{\mathrm{g}}^{t}-\frac{R_{\text {dif }}}{\lambda+\nu}\right) \mathrm{e}^{-(\lambda+\nu)\left(t-t_{\text {def }}\right)}+\frac{R_{\text {dif }}}{\lambda+\nu}, \\
& t>t_{\text {def }}, \\
N_{\mathrm{c}}(t)= & C_{1} \mathrm{e}^{-(\lambda+\nu) t}+C_{2} \mathrm{e}^{-(\lambda+\beta) t}+C_{3}
\end{aligned}
$$

where $t_{\text {def }}$ is the time of occurrence of a defect in the fuel bundle, $C_{1}, C_{2}$, and $C_{3}$ are constants depending on the isotope decay rate $\lambda$, the defect escape rate $\nu$, and release rate from fuel matrix $R_{\mathrm{dif}}$. It is evident from Eq. (13), that in case of the fuel rod rupture $t=t_{\text {def }}$ we have $N_{\mathrm{g}}=\left.N_{\mathrm{g}}^{\text {tight }}\right|_{\left(t=t_{\text {def }}\right)}$, where $N_{\mathrm{g}}^{\text {tight }}$ is the gap activity at the time of the fuel rod rupture. The simplified approximation of the fuel rod gap and MCC coolant activity behaviour before and after fuel rod rupture according to Eqs. (12)-(14) is given in Fig. 2.

The result of the iodine activity dependence on time allows us to assess the situation at the moment of the MCC coolant sampling for laboratory measurements. The equilibrium of ${ }^{131} \mathrm{I}$ is reached after some 20 days of operation after the fuel rod rupture. Other shortlived isotopes of iodine reach this condition considerably faster. Based on this analysis we derive the ratio for the $i$ th radionuclide of the measured coolant activity $A_{i}^{\text {meas }}$ to the one in the steady state condition $A_{i}^{\text {stat }}$, the correction factor $F_{i}$ :

$$
F_{i}=\frac{A_{i}^{\text {meas }}}{A_{i}^{\text {stat }}} .
$$

We apply corrections as follows:

$$
\left(\frac{R}{y}\right)_{\text {meas }}=\frac{\lambda+\beta_{\mathrm{p}}}{\lambda} \frac{A_{\mathrm{c}}}{y F_{i}} .
$$
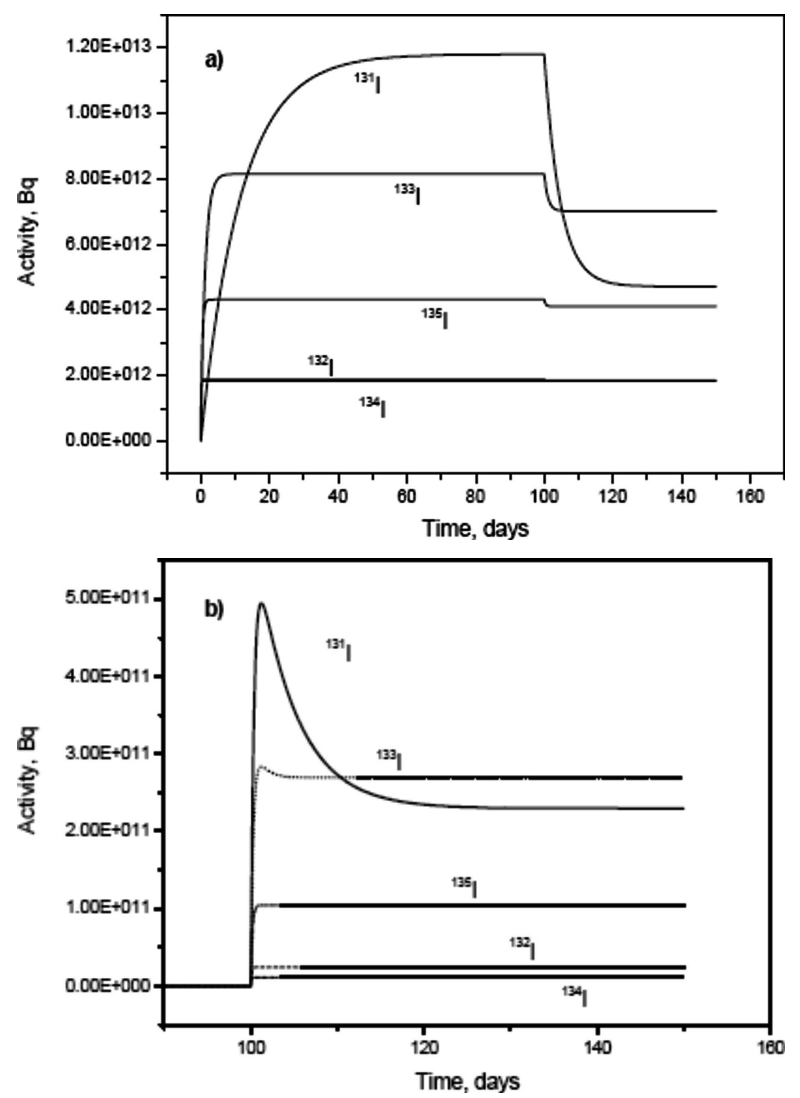

Fig. 2. Activity behaviour of iodine isotopes in (a) RBMK-1500 fuel gap and (b) MCC coolant.

Correction factor $F_{i}$ values of the iodine isotope activity in case of sampling in 10 hours after the fuel rupture are provided in Table 3. The largest correction factor is applied to ${ }^{131} \mathrm{I}$, which according to Eq. (14) needs the longest time to reach equilibrium after the fuel rod rupture. Activities of other isotopes shall be corrected considerably less due to much shorter decay times and fast equilibration of their concentration in the MCC coolant. Evaluated factor values correct the data points on the release versus decay constant plot due to the measurement in a non-stationary concentration condition. Another possible correction factor $H$ is applied in $[4,20]$ to account for the relatively long-lived precursors of the isotope of interest. For iodine isotopes this factor is close to 1 with the exception of ${ }^{132}$ I due to the long-lived precursor ${ }^{132} \mathrm{Te}\left(T_{1 / 2}=3.26 \mathrm{~d}\right)$ and the resulting precursor factor $H$ in the range 6-12 [4, 20]. In our study we exclude correction of data by the precursor factor due to the uncertain value of $H$ provided 

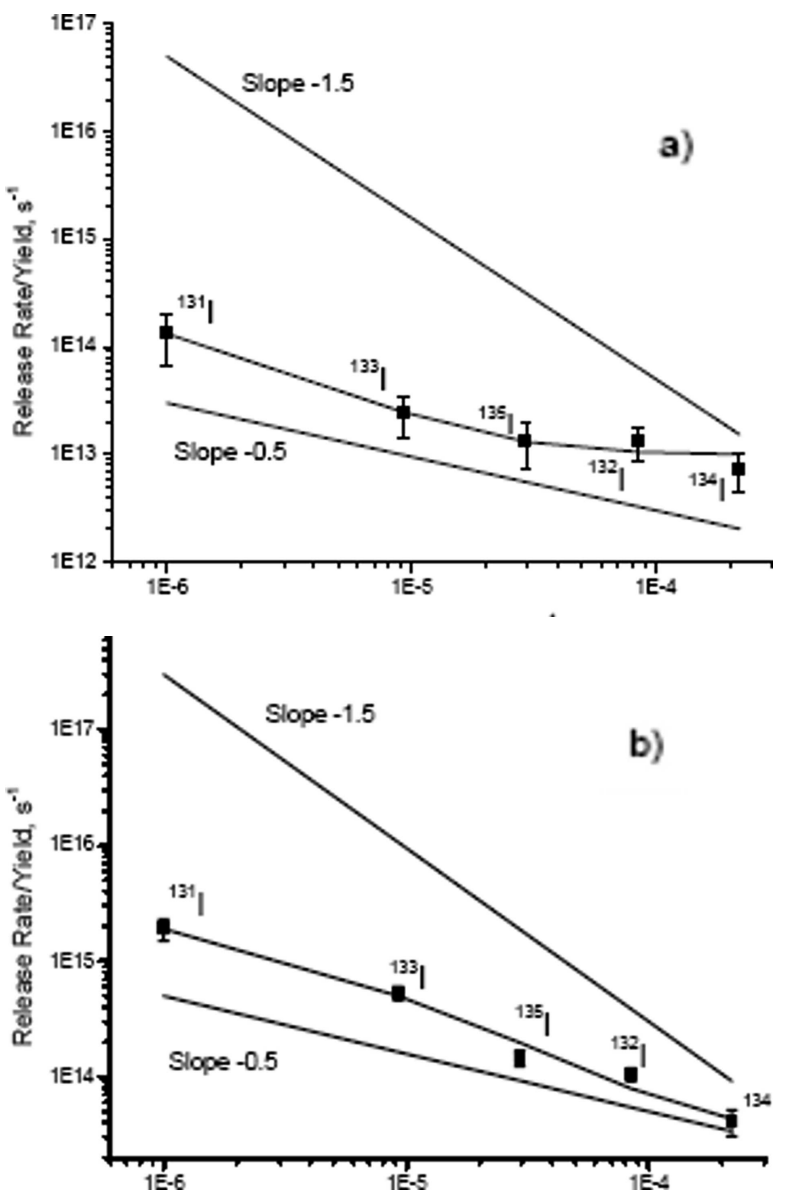

Fig. 3. Fitting of model (Eq. (7)) to measured RBMK-1500 coolant activity data of fuel rupture occurred on (a) 12.08.2005 and (b) 07.06.2006 (Table 4).

in the literature. On the other hand, the application of $H$ would only have some influence on the evaluated release from tramp uranium, however, it would insignificantly affect the release parameters $D^{\prime}$ and $\nu$ of the fuel matrix and cladding defect.

\section{Results of MCC coolant activity modelling and discussion}

We applied the correction factor $F_{i}$ to the measured iodine coolant activities and performed fitting of all available data sets characterizing MCC activity after fuel failure. An example of fitting is given in Fig. 3. The investigated fuel rupture cases are given in Table 4. Evaluated model parameters are summarized in Table 5.

Rupture cases of fuel assemblies 1 and 2 are similar on the basis of fitted parameter values (Table 4). Especially the gap release rate coefficient $\nu$ is similar in these cases. Difference of $D^{\prime}$ is more pronounced; however, this could be the consequence of nonlinearity of $D^{\prime}$. The power of fuel assembly 3 (Table 4) before refuelling was $2.9 \mathrm{MW}$ compared to $\sim 2.6 \mathrm{MW}$ of assemblies 1 and 2. The temperature of fuel matrix of assembly 3 was higher and diffusion was more intensive as well. This is confirmed by larger calculated $D^{\prime}$ values for assembly 3 compared to assemblies 1 and 2 . The release rate from tramp uranium $c$ agrees within the evaluated parameter errors for all analysed fuel assemblies. Evaluated model values and their arithmetic or geometric average values are comparable to those presented in [4] for the CANDU reactor (Table 5). Differences can be explained by probably different defect sizes, tramp uranium contamination, and different fuel parameters, such as grain size of the fuel pellet, fuel temperature, and the fuel pellet design.

The analysed fuel assembly 3 (Table 4) represents a different situation from assemblies 1 and 2 . The gap release rate coefficient $\nu$ differs by up to one order of magnitude and is larger in case of assembly 3 . It means that the defect size of assembly 3 is larger than that of assemblies 1 and 2. This is confirmed by the measured actual iodine activities (e. g., ${ }^{131}$ I specific activity $\sim 2.0 \cdot 10^{5} \mathrm{~Bq} / 1$ and $\sim 1.5 \cdot 10^{6} \mathrm{~Bq} / 1$ for assemblies 1 and 3 ) and can be seen from Fig. 3 as well. Moreover, the slope of fitted model curves in Fig. 3 in the case of assembly 3 is smaller and closer to the -0.5 value than in the case of assemblies 1 and 2. According to Eq. (10), large defects $(\lambda \ll \nu)$ are represented by the $\lambda^{-1 / 2}$ dependence with the -0.5 slope on the logarithmic plot. Small defects and long holdup of FP in the gap would result in the $\lambda^{-3 / 2}$ or -1.5 slope on the logarithmic plot (Fig. 3). The independent part of the $R / y$ curve in the cases of fuel assemblies 1 and 2 describes the release from tramp uranium. In the case of assembly 3 this phenomenon is insignificant compared to the release from the defective fuel element.

\section{Conclusions}

We applied the formalism proposed by Lewis and Husain [4] for the analysis of iodine release from defective fuel to the MCC of the RBMK-1500 reactor. The analysis of the iodine activity behaviour after the fuel rupture shows that the MCC coolant activity of the RBMK-1500 reactor is in a non-stationary condition. The proposed method allows evaluating the correction factors needed to predict activities of short-lived iodine isotopes when the activity equilibrium between the fuel gap and the MCC coolant is reached. The model was fitted to the experimental data of four fuel 
Table 4. Characteristics of defective fuel elements.

\begin{tabular}{cccccc}
\hline Fuel assembly & $\begin{array}{c}\text { Initial enrichment, } \\
\%{ }^{235} \mathrm{U}\end{array}$ & $\begin{array}{c}\text { Burnup, } \\
\mathrm{MW} \mathrm{d} / \mathrm{kg} \mathrm{U}\end{array}$ & $\begin{array}{c}\text { Power of fuel } \\
\text { assembly, MW }\end{array}$ & Discharge date & $\begin{array}{c}\text { Date of } \\
\text { measurement }\end{array}$ \\
\hline $1 a$ & 2.6 & 9.53 & 2.60 & 12.08 .2005 & 12.08 .2005 \\
$1 b$ & 2.6 & 9.53 & 2.60 & 12.08 .2005 & 12.08 .2005 \\
2 & 2.6 & 19.56 & 2.59 & 13.08 .2005 & 13.08 .2005 \\
3 & 2.6 & 10.32 & 2.90 & 07.06 .2006 & 07.06 .2006 \\
\hline
\end{tabular}

Table 5. Evaluated model parameter values for defective fuel assemblies.

\begin{tabular}{ccccc}
\hline Fuel assembly & $\begin{array}{c}\text { Gap escape rate } \\
\text { coefficient } \nu, \mathrm{s}^{-1}\end{array}$ & $\begin{array}{c}\text { Diffusive release } \\
\text { coefficient } A, \mathrm{~s}^{-1}\end{array}$ & $\begin{array}{c}\text { Release from tramp } \\
\text { uranium } c, \mathrm{~s}^{-1}\end{array}$ & $\begin{array}{c}\text { Diffusion coefficient } \\
D^{\prime}, \mathrm{s}^{-1}\end{array}$ \\
\hline $1 a$ & $2.8 \mathrm{E}-06 \pm 1.9 \mathrm{E}-06$ & $3.19 \mathrm{E}+11 \pm 1.07 \mathrm{E}+11$ & $1.30 \mathrm{E}+13 \pm 4.68 \mathrm{E}+12$ & $2.22 \mathrm{E}-09$ \\
$1 b$ & $5.9 \mathrm{E}-06 \pm 2.9 \mathrm{E}-06$ & $2.20 \mathrm{E}+11 \pm 1.75 \mathrm{E}+10$ & $9.54 \mathrm{E}+12 \pm 3.49 \mathrm{E}+12$ & $1.06 \mathrm{E}-09$ \\
2 & $6.1 \mathrm{E}-06 \pm 6.5 \mathrm{E}-06$ & $1.06 \mathrm{E}+11 \pm 4.13 \mathrm{E}+10$ & $6.66 \mathrm{E}+12 \pm 3.25 \mathrm{E}+12$ & $2.46 \mathrm{E}-10$ \\
3 & $2.5 \mathrm{E}-05 \pm 7.0 \mathrm{E}-06$ & $1.87 \mathrm{E}+12 \pm 4.72 \mathrm{E}+10$ & $3.75 \mathrm{E}+13 \pm 3.04 \mathrm{E}+13$ & $6.15 \mathrm{E}-08$ \\
Average & $4.40 \mathrm{E}-05$ & $5.16 \mathrm{E}+11$ & $1.55 \mathrm{E}+13$ & $1.32 \mathrm{E}-08$ \\
Geometric mean & $1.35 \mathrm{E}-05$ & $2.45 \mathrm{E}+11$ & $1.27 \mathrm{E}+13$ & $1.19 \mathrm{E}-09$ \\
CANDU reactor $[4]$ & $1.38 \mathrm{E}-06$ & $8.38 \mathrm{E}+11$ & $5.22 \mathrm{E}+13$ & $6.80 \mathrm{E}-10$ \\
\hline
\end{tabular}

rupture cases. The analysis of the evaluated model parameters allows us to clearly identify and separate different fuel cladding defect situations. Larger cladding defects are represented by the larger gap escape rate coefficients. The evaluated diffusion coefficient can be correlated with the fuel assembly power, however, its value is more dispersed due to nonlinear dependence on fuel parameters. The results show that the method developed by Lewis and Husain [4] can be applied to the analysis of the iodine release from the RBMK-1500 reactor defective fuel to the MCC coolant.

\section{Acknowledgements}

This study was supported by the Lithuanian State Science and Studies Foundation in the frame of Project C-19/2006. We would like to kindly thank the Ignalina NPP personnel for granted permission to use the operational data related to the physical characteristics of the RBMK-1500 reactor MCC coolant.

\section{References}

[1] IAEA-TECDOC-1345, Fuel failure in water reactors: Causes and mitigation, in: Proceedings of a Technical Meeting (Bratislava, Slovakia, June 2002).

[2] W. Müller, Activity determination - an overview, in: Determination and Declaration of Nuclide Specific Activity Inventories in Radioactive Wastes, International Workshop (Cologne, Germany, 2001) pp. 1-10.

[3] F.C. Iglesias, B.J. Lewis, P.J. Reid, and P. Elder, Fission product release mechanisms during reactor accident conditions, J. Nucl. Mater. 270, 21-38 (1999).
[4] B.J. Lewis and A. Husain, Modelling the activity of ${ }^{129} \mathrm{I}$ in the primary coolant of a CANDU reactor, J. Nucl. Mater. 312, 81-96 (2003).

[5] V. Remeikis and A. Jurkevicius, Evolution of the neutron sensor characteristics in the RBMK-1500 reactor neutron flux, Nucl. Eng. Des. 231, 271-282 (2004).

[6] K. Almenas, A. Kaliatka, and E. Ušpuras, Ignalina RBMK-1500. A Source Book. Extended and Updated Version (Lithuanian Energy Institute, Kaunas, 1998).

[7] General safety regulations of nuclear power plants during design, construction, and operation (OPB-82), Atomic Energy 54 (2), 151-160 (1983) [In Russian].

[8] B.J. Lewis, Fundamental aspects of defective nuclear fuel behaviour and fission product release, J. Nucl. Mater. 160, 201-217 (1988).

[9] Instructions for Operation of Installation of Bypass Purification of MCC Water of Building 101/1,2 of Units 1, 2, PTO-ED-0912-116V7 (Ignalina NPP, 2004) [in Russian].

[10] P. Lösönen, On the behaviour of intragranular fission gas in $\mathrm{UO}_{2}$ fuel, J. Nucl. Mater. 280, 56-72 (2000).

[11] J.A. Turnbull, R.J. White, and C. Wise, The diffusion coefficient for fission gas atoms in uranium dioxide, in: IAEA Technical Committee Meeting on Water Reactor Fuel Element Computer Modelling in Steady State, Transient and Accident Conditions, Preston, England (1988).

[12] J.A. Turnbull, C.A. Friskney, J.R. Findlay, F.A. Johnson, and A.J. Water, The diffusion coefficient of gaseous and volatile species during the irradiation of uranium dioxide, J. Nucl. Mater. 107, 168-184 (1982).

[13] H.J. Matzke, Gas release mechanisms in $\mathrm{UO}_{2}$ - a critical review, Rad. Effects 53, 219-242 (1980).

[14] B.J. Lewis, R.D. MacDonald, and H.W. Bonin, Release of iodine and noble gas fission products from de- 
fected fuel elements during reactor shutdown and startup, Nucl. Technol. 92, 315-324 (1990).

[15] B.J. Lewis, Fission product release from nuclear fuel by recoil and knockout, J. Nucl. Mater. 148, 28-42 (1987).

[16] C. Wise, Recoil release of fission products from nuclear fuel, J. Nucl. Mater. 136, 30-47 (1985).

[17] Monitoring Schedule for Ensuring the Radiation Protection and Safety at Ignalina NPP for 2006, PTO-ED0515-2B7 (Ignalina NPP, 2005) [in Russian].
[18] Instructions for Carrying out Radiometric and Dosimetric Measurements at Ignalina NPP, PTO-ED-0512$5 B 8$ (Ignalina NPP, 2002) [in Russian].

[19] A Set of Methodics to be Used for Measurements of Radionuclide Composition in Technological Media, PTOED-0528-1B3 (Ignalina NPP, 2005) [in Russian].

[20] B.J. Lewis, C.E.L. Hunt, and F.C. Iglesias, Source term of iodine and noble gas fission products in the fuel-tosheath gap of intact operating nuclear fuel elements, J. Nucl. Mater. 172, 197-205 (1990).

\title{
JODO IŠLAKŲ IŠ PAŽEISTŲ RBMK-1500 REAKTORIAUS KURO ELEMENTŲ ANALIZE்
}

\author{
G. Klevinskas, L. Juodis, R. Plukienė, A. Plukis, V. Remeikis \\ Fizikos institutas, Vilnius, Lietuva
}

\begin{abstract}
Santrauka
Branduolinio reaktoriaus darbo metu urano dioksido kuro tabletėse susidaro dalijimosi produktai (DP), kurie migruoja i tarpeli tarp kuro elemento tablečių ir cirkonio apvalkalo, o per pastarojo defektus patenka i reaktoriaus pagrindinio cirkuliacinio kontūro (PCK) vandenị. Prognozuoti DP sklaidą reaktoriaus kontūre yra svarbu, nes tai leidžia įvertinti avariju pasekmes bei numatyti ilgalaikị radiacini poveiki aplinkai ir gyventojams galutinai palaidojus eksploatacijos metu susidariusias DP užterštas radioaktyviąsias atliekas. Atsižvelgus į RBMK-1500 reaktoriaus PCK vandens aktyvumo matavimo specifiką, šiame darbe pateiktas papildytas DP
\end{abstract}

balanso reaktoriaus pagrindiniame cirkuliaciniame kontūre modelis ir ivertintas radionuklidu koncentracijos kuro tarpelyje ir reaktoriaus pagrindiniame cirkuliaciniame kontūre kitimas kuro elemento cirkonio apvalkalo trūkio atveju bei pasiūlytos ir ivertintos atitinkamos radionuklidų koncentracijos pataisos. Išanalizuotas jodo izotopu išsiskyrimas iš kuro RBMK-1500 reaktoriaus atveju. Pateikiami jodo radionuklidų išlaku i RBMK-1500 reaktoriaus pagrindinị cirkuliacinị kontūrą modeliavimo ir analizės rezultatai. Apskaičiuoti jodo izotopu sklaidos RBMK-1500 reaktoriaus kontūre modelio parametrai ir efektinis jodo difuzijos koeficientas $D^{\prime}$ RBMK-1500 reaktoriaus branduoliniame kure. 